\title{
CONVERXENCIA E DIVERXENCIA EN CERTAS ESTRUTURAS MORFOSINTÁCTICAS DO GALEGO
}

\author{
Bieito Silva Valdivia
}

Universidade de Santiago de Compostela

\section{INTERFERENCIA E CONVERXENCIA LINGÜÍSTICAS}

O contacto prolongado entre dúas linguas xera procesos de 'cambio de lingua', amplamente estudados en múltiples contextos, e tamén episodios máis ou menos extensos de 'cambios na lingua', en especial no que se refire á variedade minorizada, que adoita ser non só recesiva desde o punto de vista social senón tamén dependente desde a perspectiva estrutural. Desta maneira, moitos dos cambios que se producen en linguas que conviven nun mesmo territorio e que son empregadas polos mesmos individuos téñense atribuído a fenómenos de interferencia do outro idioma.

$\mathrm{Na}$ descrición dos cambios lingüísticos cómpre, porén, refugar explicacións simplistas que case nunca se corresponden coa realidade. A lingüística estrutural teimou durante décadas en apoiarse en razóns exclusivamente intrínsecas aos propios códigos para xustificar as modificacións que se produciran historicamente nos mesmos. A partir da década de 1950 os factores sociais comezan a compartir protagonismo explicativo cos estritamente estruturais, nunha perspectiva pluridisciplinar e integradora que defende xa con claridade Weinreich (1953/1974: 23) cando afirma que os estudos puramente lingüísticos das linguas en contacto teñen que coordinarse cos estudos extralingüísticos sobre o bilingüismo e os fenómenos relacionados con el. O desenvolvemento da sociolingüística e a importancia que acadou como disciplina científica nas décadas posteriores fixo que se subliñase a importancia dos fenómenos históricos, sociopolíticos e culturais, por considerar que son estes os que condicionan de maneira máis decisiva o tipo de contacto e as súas consecuencias lingüísticas e sociolingüísticas: Thomason e Kaufman (1988: 35) afirman, por exemplo, que a historia sociolingüística dos falantes é o factor principal do resultado lingüístico do contacto entre linguas e que os factores puramente lingüísticos, aínda sendo relevantes, son totalmente secundarios. 
Esta variación que se apreciou no foco explicativo dos cambios lingüísticos ao longo da historia dá conta da súa complexidade e debe servir para reforzar a tese da multicausalidade dos mesmos, de que a prevalencia duns determinados factores non se pode entender como exclusividade e de que na historia dunha lingua concorren adoito influencias foráneas e tendencias endóxenas que unhas veces poden servir para frear -e mesmo neutralizarprocesos de cambio e outras, polo contrario, para aceleralos.

M. Sala resolve o debate sobre a causalidade dos cambios lingüísticos en situacións de contacto cunha afirmación de compromiso na que alude explicitamente a esa combinación de factores:

A veces es bastante difícil precisar si un fenómeno resulta de una evolución interna o de una influencia externa (...) Algunos fenómenos son consecuencia de una tendencia interna fortalecida por una influencia externa. (Sala, 1998: 314)

E, desde outra perspectiva, S. G. Thomason formulaba tamén hai poucos anos a tese da "unpredictability of contact effects", defendendo que as pescudas sobre predicións deterministas do cambio inducido polo contacto idiomático fallaran radicalmente, que os prognósticos de posibles resultados lingüísticos son máis sociais ca lingüísticos, e que unha cousa é dicir que un determinado factor é necesario para que se produza o cambio e outra que o provoque inevitablemente. As conclusións da súa argumentación e dos diversos exemplos nos que a apoia sintetízaas nos seguintes termos:

First, language change is unpredictable because even the most natural changes often fail to occur; therefore, although it is often possible to state NECESSARY conditions for change, it is never possible to state SUFFICIENT conditions for change. And second, since speakers can and do change their language deliberately, and since counterexamples have been provided to all the linguistic constraints that have been proposed on contact-induced change, it is extremely unlikely that there are nontrivial linguistic constraints on contact effects (Thomason, S. G, 2000: 174).

Estas cautelas na explicación causal dos cambios lingüísticos en situacións de contacto están especialmente xustificadas ao referírmonos a variedades lingüísticas emparentadas xeneticamente, pois é nestes casos cando a propia evolución interna pode levar a situacións de converxencia entre elas. Weinreich (1953/74) citaba a proximidade estrutural entre dous sistemas lingüísticos como un dos factores máis favorecedores da interferencia, aínda que non aludía á posibilidade de que estas interferencias puideran enmascarar resultados evolutivos autónomos. Van Overbecke (1976), pola súa banda, 
referíase á importancia da economía lingüística como factor que leva en moitos contextos de contacto idiomático á simplificación e ao reforzamento de formas comúns en prexuízo das formas diferenciais. Lope Blanch (1981) falaba da debilitación das normas das linguas en contacto como causa dun polimorfismo lingüístico máis ou menos intenso que pode derivar na aparición de formas lingüísticas alleas ao sistema orixinario ou favorecer o desenvolvemento de posibilidades non realizadas con anterioridade; un afrouxamento normativo citado xa por Malmberg un par de décadas atrás cando afirmaba o seguinte:

La coexistence de deux systèmes amène nécessairement un affaiblissement des normes et, de là, un manque de stabilité, susceptible de conditionner une évolution' (Malmberg, 1959: 250)

Nas investigacións realizadas no ámbito peninsular fixéronse tamén reiteradas referencias ao fenómeno da converxencia entre os sistemas lingüísticos como factor engadido ao da interferencia estrita. Citemos algúns exemplos:

Ll. Payrató remata as súas consideracións sobre o carácter catalizador da interferencia na evolución das linguas coa seguinte conclusión:

Dues llengües emparentades genèticament i estructuralment semblants (...) solen tenir tendències d'evolució molt o bastant similars, les convergències (espontànies) de desenvolupament entre aquests idiomes, doncs, són un fet lògic i corrent de l'evolució lingüística. (Payrató, 1985: 182)

Blas Arroyo formula dúbidas sobre a natureza dalgúns fenómenos gramaticais do castelán de Valencia que se catalogan convencionalmente como interferencias do catalán. Pecha a súa exposición sobre un epígrafe que titula en forma interrogativa como "iInterferencia o convergencia?" coas seguintes palabras:

Debemos aceptar consiguientemente que nos hallamos ante hechos que pueden ser definidos bajo etiquetas más amplias que la simple interferencia. O dicho de otro modo: la interferencia es en ocasiones sólo un factor más, aunque de indudable importancia, en el desarrollo y en la extensión social de un determinado fenómeno lingüístico. (Blas Arroyo, 1993: 30)

E, tamén no contacto catalán-castelán, pero neste caso entre unha poboación constituída por un colectivo de universitarios de Barcelona, Carmen Hernández somete a unha revisión similar algúns dos exemplos que se tratan habitualmente como catalanismos: 
Algunos ejemplos, pese a estar documentados también como casos de interferencia del catalán, plantean algunas dudas. El uso del posesivo en lugar del pronombre personal precedido de preposición (delante de mî) se halla documentado en las gramáticas del español como un uso vulgar de la lengua que parece que va extendiéndose progresivamente, y no por catalanismo; por lo tanto, podríamos hallarnos ante un caso de convergencia de dos fenómenos: por una parte, un uso vulgar cada vez más común en español y, por otra, la existencia en catalán de esa misma estructura, normativa y muy productiva (Hernández, 1997: 635)

\section{CONVERXENCIA E DIVERXENCIA MORFOSINTÁCTICA ENTRE O GALEGO} E O CASTELÁN

Entendemos que a reflexión desenvolvida no epígrafe anterior é aplicable na súa totalidade á lingua galega: é indiscutible que a súa evolución estivo moi condicionada polo contacto dependente que mantivo co castelán ao longo da historia; pero está demostrado tamén que moitos procesos de converxencia con este idioma responden a derivas endóxenas, aínda que estas se puidesen ver favorecidas por esa situación de contacto.

As páxinas que seguen recollen unha aproximación a varias estruturas morfolóxicas e sintácticas do galego que ofrecen diversas realizacións posibles: unha converxente ou máis próxima ao castelán e outra diverxente ou máis afastada. Trátase dun achegamento á situación social das mesmas entre alumnado de $4^{\circ}$ da ESO co que se pretende testar a competencia desta poboación escolar en relación con esas diversas alternativas que ofrece o idioma e tamén, aínda que máis indirectamente, comprobar a dispoñibilidade das mesmas no repertorio verbal deses suxeitos. Consiste, xa que logo, nunha radiografía de situación que achega información sobre esas dúas cuestións, pero sen pescudar nas súas causas e sen pretender, en consecuencia, atribuír os resultados obtidos á exclusiva influencia do castelán.

Como marco teórico partimos do concepto de 'interferencia negativa' formulado por Coseriu (1977) e aplicado ao contexto galego por Kabatek (1991 e 2000), que se basea na idea de que na práctica lingüística do individuo bilingüe non ten importancia só o que di, senón tamén o que non di; é dicir, as súas realizacións 'negativas' por mor da interferencia. É un concepto que ten dúas facianas contrapostas e non excluíntes: por unha banda, a non realización das posibilidades diverxentes dunha lingua por darlle prioridade aos elementos que ten en común coa outra coa que está en contacto, e, en sentido contrario, a preferencia polos elementos distintos, coa conseguinte non realización dos elementos comúns. 
Os dous son para estes autores procesos que hai que incluír dentro da interferencia, porque supón escollas lingüísticas condicionadas pola outra variedade idiomática en presenza; e os dous traducen unha resposta 'negativa' do falante, no sentido de que se ve limitado no seu uso lingüístico por unha influencia indirecta desoutra lingua. Porén, aínda que se trate de procesos interrelacionados, adoitan responder a actitudes idiomáticas moi distintas e teñen consecuencias sociolingüísticas contrapostas, especialmente cando se trata dunha lingua subordinada: o diferencialismo asóciase con posturas de autoafirmación e serve para profundar nos trazos de identificación grupal e idiomática, mentres que a preferencia polas realizacións comúns contribúe máis ben a esvaecer eses contornos diferenciais e á asimilación progresiva pola lingua dominante.

Polo que se refire en concreto á 'interferencia negativa por converxencia', trátase dun proceso de simplificación lingüística mediante o cal os falantes bilingües -ou que viven en contextos bilingües- tenden a situarse nas formas menos marcadas e formalmente máis próximas, e que no ámbito do léxico -o máis estudado- se manifesta na perda de funcionalidade dos termos máis diferenciados a favor dos que mostran unha maior correspondencia nos dous idiomas e na conseguinte desaparición dos mesmos dos usos cotiáns e espontáneos.

Este feito foi observado xa por Van Overbeke (1976), quen interpretaba a redución de vocabulario provocada por este tipo de interferencia como un mecanismo de economía memorística que levaba aos falantes a se instalaren preferentemente en vocábulos baleiros e dunha 'valencia' moi ampla, susceptibles de seren empregados nas dúas linguas. E, aínda que non se poidan extraer conclusións precipitadas sobre o empobrecemento léxico que se pode derivar deste tipo de procesos, parece claro que este é un risco evidente, especialmente para o idioma subordinado, de non se contrarrestar con modelos enriquecidos a través da escola, dos medios de comunicación e doutros usos públicos.

A 'interferencia por converxencia' non atopa, en principio, unha penetración tan doada na morfoloxía e na sintaxe, por seren niveis lingüísticos máis estruturados e menos abertos á variación ca o léxico; pero isto non impide que opere naqueles casos en que o sistema da lingua ofrece varias alternativas formais, das que unha delas é concorrente coa do outro idioma, tal como teremos ocasión de comprobar nos datos que se ofrecen a continuación.

No tocante á 'interferencia por diverxencia' responde a miúdo a posturas diferencialistas e de autoafirmación da singularidade lingüística; un propósito que no caso de idiomas coma o galego que viviu durante séculos baixo o teito social e estrutural do castelán se identifica nalgúns falantes cun compromiso especial co idioma. O problema, desde o punto de vista sociolin- 
güístico, é que esta actitude que poderiamos definir de 'lealdade lingüística' se mestura con outros comportamentos moito máis inconscientes ou simplemente dependentes de modas dominantes nalgún sector social. E, desde a perspectiva máis lingüística, o perigo está en que a escolla sistemática das formas diverxentes pode levar, por unha banda, a unha expansión do seu uso a contextos indebidos e, por outra, á exclusión inxustificada das correspondentes formas converxentes ata o punto de que sexan sentidas por eses falantes como non lícitas ou carentes de autenticidade idiomática.

R. Álvarez chamaba a atención sobre estes riscos hai xa uns dez anos en relación con unha das construcións que mellor singulariza o galego fronte ó castelán, pero que se atopa sometida nas últimas décadas a un proceso en boa maneira contraditorio: a perda de vitalidade nos seu ámbito de uso máis tradicional (a oralidade coloquial) acompañada dun uso abusivo e ás veces incorrecto na lingua escrita e na oralidade formal:

Debido ó desexo de protexe-lo infinitivo conxugado, nos últimos tempos déronse usos erróneos e abusivos (...); conviría termos unha boa descrición gramatical para separar usos forzados pola discriminación positiva a favor do infinitivo conxugado, de posibilidades tradicionais que pola súa infrecuencia van caendo en desuso e son virtualmente descoñecidas por amplos sectores da comunidade galegofalante. (Álvarez, 1994: 28)

Converxencia e diverxencia son, xa que logo, dúas maneiras de resolver a escolla de formas lingüísticas nunha situación de contacto que, sendo aparentemente contrapostas, traducen adoito unha mesma relación de dependencia idiomática e introducen factores de inestabilidade lingüística que poden derivar en cambios na estrutura das variedades implicadas.

\section{MOSTRA, INSTRUMENTOS E OBXECTIVOS DA INVESTIGACIÓN}

\section{Poboación e mostra}

A poboación na que se centrou a análise destes procesos de converxencia e diverxencia morfosintáctica foi o alumnado de $4^{\circ}$ curso de Educación Secundaria Obrigatoria, unha poboación que, pola súa idade (16 anos) e nivel académico (dez anos, como mínimo, de aprendizaxe da lingua galega), nos parecía representativa tanto da deriva que están sufrindo estes fenómenos entre a mocidade coma do seu nivel de dominio da norma lingüística.

Esta poboación estaba distribuída, segundo datos da Consellería de Educación e Ordenación Universitaria da Xunta de Galicia correspondente ao ano académico 2000-2001, do seguinte xeito: 


\begin{tabular}{l|r|r|r|r|r}
\hline & \multicolumn{2}{|c|}{ E. PÚBLICO } & \multicolumn{2}{c|}{ E. PRIVADO } & \multirow{2}{*}{ TOTAIS } \\
\cline { 2 - 5 } & ALUMNOS & \multicolumn{1}{|c|}{ ALUMNAS } & ALUMNOS & \multicolumn{1}{|c|}{ ALUMNAS } & \multicolumn{1}{c}{12.640} \\
A CORUÑA & 4.679 & 4.653 & 1.695 & 1.613 & 12.739 \\
LUGO & 1.428 & 1.616 & 381 & 339 & 3.764 \\
OURENSE & 1.124 & 1.124 & 516 & 566 & 3.330 \\
PONTEVEDRA & 3.751 & 4.074 & 1.662 & 1.649 & 11.136 \\
TOTAL GALICIA & 10.982 & 11.467 & 4.254 & 4.167 & 30.870 \\
\hline
\end{tabular}

A selección da mostra realizouse atendendo ás variables de hábitat e titularidade de centro, que, implicitamente, supuñan tamén unha estratificación sociolingüística e de sexo. A distribución do alumnado da mostra de acordo con esas variables foi a seguinte:

\begin{tabular}{l|r|r|r|r}
\hline \multicolumn{2}{c|}{ Urbano } & \multicolumn{1}{c|}{ Vilego } & \multicolumn{1}{c}{ Rural } & \multicolumn{1}{c}{ Total } \\
\hline C. Públicos & 267 & 351 & 235 & 853 \\
C. Privados & 249 & 122 & - & 371 \\
Total & 516 & 473 & 235 & 1224 \\
\hline
\end{tabular}

Realizados os cálculos estatísticos pertinentes, a ficha técnica da investigación quedou do seguinte modo:

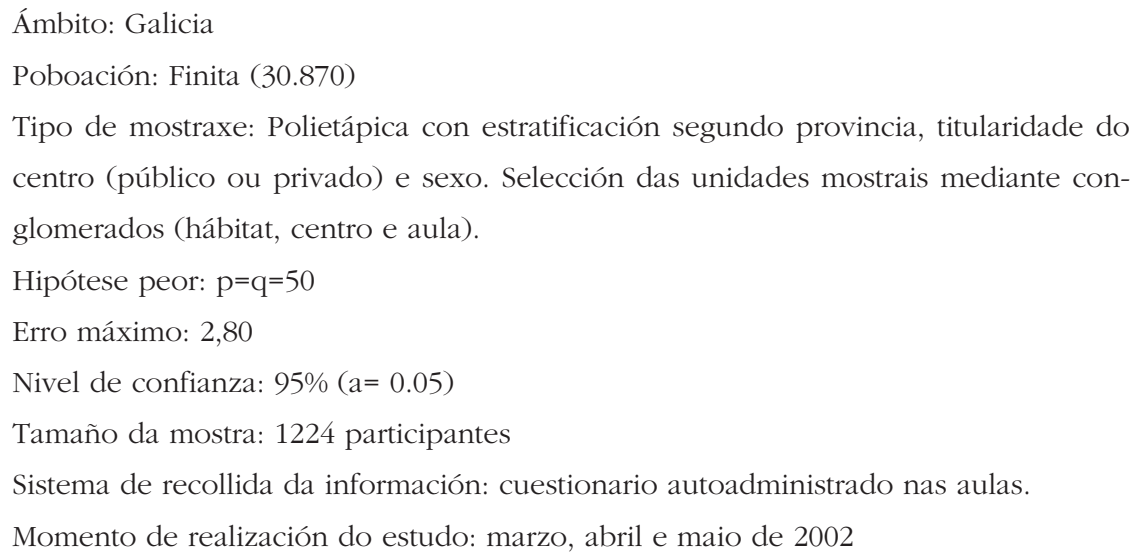

Para as análises finais a mostra quedou reducida a 1162 participantes, debido ao alto número de non respostas nos 62 casos eliminados. Dado que nestes casos non existía un patrón determinado respecto a ningunha variable de análise considerada, non se valorou como unha falta de información transcendente a súa eliminación. A mostra resultante é igualmente representativa, cun nivel de erro máximo de 2,88. 


\section{INSTRUMENTOS UTILIZADOS NA INVESTIGACIÓN}

$\mathrm{Na}$ investigación utilizouse un cuestionario organizado fundamentalmente a partir de items sociolingüísticos e escolares e catro probas nas que os estudantes debían resolver unha serie de actividades a partir duns textos:

-Na proba 1 presentábanse textos en galego relacionados cos fenómenos lingüísticos analizados para que indicasen se había algún erro desde o punto de vista normativo e, nese caso, que o corrixisen.

-Na proba 2 solicitábaselles que completasen uns textos que se lles ofrecían en galego, debendo para iso activar as estruturas morfosintácticas que eran obxecto de análise.

-Na proba 3 debían traducir ao galego uns textos casteláns nos que se integraban esas mesmas construcións.

-Finalmente, nunha proba 4 ofrecíanselles varias realizacións formais para unha mesma estrutura lingüística (unha converxente co castelán, outra diverxente e algunha agramatical) para que realizasen dúas tarefas sobre as mesmas: definirse sobre a corrección / incorrección de cada unha delas e seleccionar entre todas aquela coa que se identificaban máis.

\section{OBXEcTIVOS}

Esta aproximación á situación dalgunhas estruturas morfosintácticas que ofrecen varias realizacións posibles trataba de achegar unha información sobre o coñecemento desas distintas formas históricas no idioma por parte do colectivo analizado e, máis indirectamente, sobre a dispoñibilidade das mesmas no seu repertorio verbal e sobre o grao de identificación con cada unha delas. Unha información referida en todos os casos a un sector de poboación que, tanto pola súa idade coma pola súa formación lingüística, consideramos estratéxica para establecer prospeccións sobre o futuro desas formas lingüísticas.

De xeito máis explícito, pensamos que os datos obtidos deben servir para:

-Coñecer o nivel de competencia idiomática do alumnado de $4^{\circ}$ da ESO sobre as diferentes alternativas formais que ofrece o galego para resolver cada un deses contextos lingüísticos.

-Realizar un achegamento á dispoñibilidade de cada unha desas formas no repertorio verbal dos estudantes, especialmente no que se refire ás realizacións máis diverxentes. 
-Coñecer o grao de identificación dese alumnado con cada unha desas posibilidades formais.

-Como derivación de todo o anterior, realizar algunhas extrapolacións sobre a situación desas formas entre a mocidade e establecer prospeccións sobre a súa vitalidade no futuro próximo.

A seguir presentamos as estruturas morfolóxicas e sintácticas que foron obxecto de análise e que consideramos representativas do que viñemos denominando 'interferencia negativa por converxencia ou por diverxencia', xunto cos textos en que se apoiou cada unha en cada proba e os resultados máis relevantes obtidos na investigación.

\section{ESTRUTURAS MORFOSINTÁCTICAS ANALIZADAS E RESULTADOS}

\section{1. Posición do clítico nas perífrases 'ter / haber que + infinitivo'}

En galego, nas perífrases de infinitivo nas que hai un nexo intermedio entre o verbo auxiliar e o auxiliado, o pronome pode ir enclítico ó infinitivo, situarse entre a conxunción e o infinitivo ou ocupar unha posición enclítica ou proclítica, segundo corresponda, ao verbo auxiliar: tes que dicirllo, tes que llo dicir, tesllo que dicir / non llo tes que dicir.

Destas tres opcións, no castelán é válida a primeira (tienes que decírselo) e a terceira, aínda que só na posición proclítica, de acordo co que é a norma xeral nesta lingua (se lo tienes que decir / no se lo tienes que decir); é dicir, pospoñerse ó infinitivo ou antepoñerse ó conxunto da perífrase, se ben a anteposición é considerada máis coloquial e na lingua escrita é máis frecuente a posposición (Gómez Torrego, 1994: 98). Neste idioma, en cambio, non é aceptable a posición intercalada entre a conxunción e o infinitivo ("tienes que se lo decir)

Os textos utilizados nas tres primeiras probas foron os seguintes:

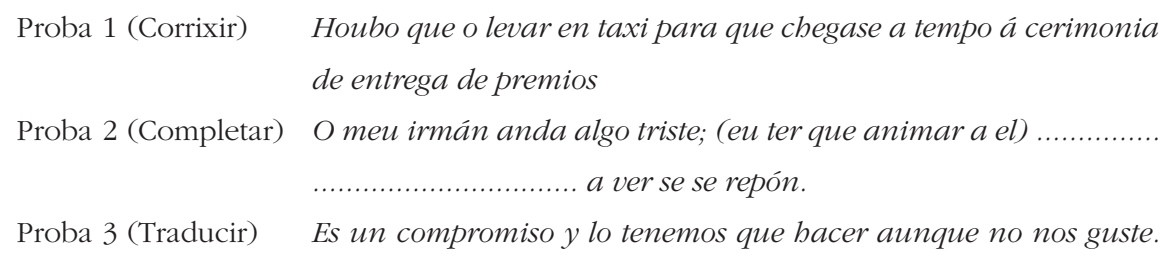

Os resultados hipotéticos son catro: 
-A énclise co infinitivo: Houbo que levalo en taxi...; ...teño que animalo a ver se se repón; ... temos que facelo aínda que non nos guste. Trataríase dunha construción coincidente entre o galego e o castelán, e válida nos dous idiomas.

-A énclise co verbo auxiliar: Hóuboo que levar en taxi...; ...téñoo que animar a ver se se repón; ... témolo que facer aínda que non nos guste. É unha alternativa correcta en galego, pero inexistente en castelán, idioma no que a construción equivalente leva o pronome anteposto (lo bubo que llevar...; lo tengo que animar...; lo tenemos que hacer)

-A anteposición absoluta: *O houbo que levar en taxi...; *...o teño que animar a ver se se repón; "...o temos que facer aínda que non nos guste. Este tipo de construcións, inexistentes en galego e que reproducen a estrutura sintáctica do castelán, debémolas considerar interferencias directas deste idioma.

-A colocación do pronome entre a conxunción e o infinitivo: Houbo que o levar en taxi...; ...teño que o animar a ver se se repón; ...temos que o facer aínda que non nos guste. Como xa se indicou máis arriba, esta é unha posibilidade exclusiva do galego, tradicional no idioma e hoxe en retroceso, aínda que se aprecie un intento de restauración a partir de usos formais e da lingua escrita.

Estas tres probas completábanse cunha $4^{a}$ na que se lles preguntaba aos estudantes sobre a corrección ou incorrección de diversas alternativas formais e na que se lles pedía que sinalasen con cál delas se identificaban máis. Os textos utilizados neste caso foron os seguintes:

Para decidir se me interesa, tería que velo primeiro

Para decidir se me interesa, tería que o ver primeiro

Para decidir se me interesa, o tería que ver primeiro

Para decidir se me interesa, tería que ver primeiro

Co conxunto destas catro probas buscábase un achegamento complementario ao comportamento do alumnado da mostra en relación con este fenómeno: na primeira ofrecíaselles unha construción no que denominamos 'alternativa marcada', de maneira que a súa substitución por outra significaría que a consideran incorrecta; é dicir, que xa non forma parte -nin sequera pasivamente- do universo lingüístico dese alumnado. A preferencia por esta ou outra das estruturas alternativas nas probas 2 e 3 orientaría sobre a vitalidade de cada unha entre esta poboación. Finalmente, a proba 4 serve para completar, desde outra perspectiva, a información sobre corrección / incorrección da proba 1; pero achega outra de valor máis cualitativo no que se 
refire ao grao de identificación desta poboación con cada unha das construcións propostas.

A continuación presentamos os resultados das tres primeiras probas agrupados en tres alternativas:

a) A que representa a forma diverxente co castelán (intercalada entre a conxunción e o infinitivo): houbo que o levar..., teño que o animar..., temos que o facer.

b) A representada por algunha das outras formas válidas (a énclise co auxiliar ou co infinitivo, esta última converxente nos dous idiomas), que trataremos conxuntamente: hóuboo que levar / houbo que levalo, téñoo que animar / teño que animalo, témolo que facer / temos que facelo.

c) A que denominamos forma castelá, que se corresponde coa próclise co auxiliar e que é unha posición válida en castelán pero anormativa en galego: *O boubo que levar, *o teño que animar, "o temos que facer.

Frecuencias e porcentaxes conseguidas por cada opción (Probas 1, 2 e 3)

\begin{tabular}{ccccc}
\hline & Forma diverxente & Outras formas válidas & Forma castelá & N.C. \\
\hline Proba 1 & $255(21,9 \%)$ & $879(75,7 \%)$ & $28(2,4 \%)$ & \\
Proba 2 & $9(0,8 \%)$ & $972(83,6 \%)$ & $125(10,8 \%)$ & $56(4,8 \%)$ \\
Proba 3 & $7(0,6 \%)$ & $889(76,5 \%)$ & $242(20,8 \%)$ & $24(2,1 \%)$ \\
\hline
\end{tabular}

Polo que se refire á proba 4, os datos referidos ás dúas preguntas que se formulaban (corrección / incorrección de cada unha das construcións e selección da que lles resultaba máis familiar ou coa que se sentían máis identificados) foron os seguintes:

Opinión sobre corrección ou incorrección (Proba 4)

$\begin{array}{cc}\text { Correcto } & \text { Incorrecto } \\ 89,9 \% & 10,1 \% \\ 20,8 \% & 79,2 \% \\ 21,5 \% & 78,5 \% \\ 83,1 \% & 16,9 \%\end{array}$

Porcentaxes globais de identificación con cada estrutura (Proba 4)

$\begin{array}{lc}\text { 1. Para decidir se me interesa, tería que velo primeiro } & 63,6 \% \\ \text { 2. Para decidir se me interesa, tería que o ver primeiro } & 2,3 \% \\ \text { 3. Para decidir se me interesa, o tería que ver primeiro } & 4,5 \% \\ \text { 4. Para decidir se me interesa, teríao que ver primeiro } & 29,5 \%\end{array}$


A distribución destes datos globais sobre 'identificación' en función de distintas variables mostrais (sociolingüísticas, de hábitat, de sexo ou escolares) non presenta diferenzas significativas.

Como conclusión dos datos extraídos das distintas probas sobre o comportamento dos estudantes da mostra en relación coa posición do clítico persoal na estrutura ter / haber + que / de + infinitivo, podemos afirmar o seguinte:

a) As construcións que sitúan o clítico en énclise co infinitivo e co auxiliar son claramente as asumidas con máis claridade como normativas entre este colectivo: 89,9\% e 83,1\%, respectivamente, na proba 4 .

Destas dúas posibilidades, a énclise do pronome co infinitivo (tería que velo) é, sen dúbida, a que mostra maior vitalidade: recorren a ela maioritariamente no momento de corrixir (proba $n^{\circ} 1$ ), completar (proba $n^{\circ} 2$ ) ou traducir (proba $n^{\circ} 3$ ), e practicamente 2 de cada 3 (o 63,6\%) escóllena como construción coa que máis se identifican. Esta preferencia mantense, sen diferenzas substanciais, en todos os segmentos da mostra, independentemente da variable de estratificación que se utilice (de hábitat, sociolingüística, etc.).

Polo que se refire á énclise do pronome co auxiliar (teríao que ver), preséntase como a segunda alternativa máis produtiva, pero en porcentaxes que se sitúan aproximadamente na metade da da énclise co infinitivo: só o 29,5\% a seleccionan como construción coa que máis se identifican, fronte ao $63,6 \%$ que se inclina por esta última. Tampouco neste caso resultan moi relevantes as distintas variables utilizadas na estratificación da mostra, se ben se aprecia un incremento nos colectivos máis galegófonos en relación cos castelanófonos e nos do rural fronte aos urbanos.

b) A intercalación do pronome entre a conxunción e o infinitivo, unha das opcións históricas no galego, é sentida como estraña pola maioría dos estudantes: só o 21,9\% non a corrixe como errónea na proba 1 e unha porcentaxe moi semellante (o 20,8\%) considéraa correcta na proba 4 . Podemos afirmar, polo tanto, que para 4 de cada 5 estudantes da mostra esta construción non forma parte da norma do galego.

O descoñecemento desa estrutura por parte deste alumnado móstrase de xeito aínda máis contundente no momento de seleccionala na súa produción lingüística (só o fai o 0,8\% na proba 2 e o 0,6\% na tradución ó galego da proba 3) ou de manifestar a súa identificación con ela na proba 4 (só o 2,3\%). O proceso de substitución case total na que parece atoparse esta construción refórzase por ser un fenómeno xeral ao conxunto da mostra, sen que se atopen diferenzas significati- 
vas entre os distintos segmentos nos que a distribuímos: máis rurais / máis urbanos, máis galegófonos / máis castelanófonos, etc. É dicir, que non parece existir ningunha illa de resistencia a ese cambio no estrato poboacional que estamos a analizar.

c) No tocante á estrutura que podemos identificar como calco do castelán (o tería que ver), observamos que, acada porcentaxes de aceptación normativa e de identificación preocupantes: o 10,8\% opta por ela na proba 2 para completar o texto que se lles propuña; o 20,8\% fai o mesmo na tradución do castelán ao galego da proba 3; o 21,5\% defínea como correcta na proba 4 , e o 4,5\% selecciónaa como alternativa coa que máis se identifican. Estas porcentaxes sitúanse en todos os casos claramente por riba das obtidas pola construción histórica do galego que definimos como diverxente, o que indica que o proceso de converxencia co castelán se está a producir non só nas formas comúns aos dous idiomas, senón tamén na construción allea ao sistema do galego que se estende por influencia directa do castelán.

Neste caso, porén, as variables sociolingüísticas e de hábitat resultan moito máis significativas: polo que se refire ao grao de identificación, esta construción é practicamente ignorada polos individuos que viven no rural, que teñen o galego como L1 ou que se desenvolven habitualmente neste idioma, mentres que acada porcentaxes próximas ao 10\% entre os máis urbanos, que teñen o castelán como L1 ou que se comunican de xeito habitual nesta lingua.

\section{2. Perifrase imperfectiva 'estar + xerundio' / 'estar a + infinitivo'}

O galego válese de distintas perífrases para expresar a acción contemplada na súa duración ou en proceso de desenvolvemento. Estas perífrases constrúense con auxiliares como levar, andar, estar, seguir, ir, vir... seguidos do xerundio, que é unha forma verbal que implica xa de por si duración; pero na maior parte dos casos o xerundio pode substituírse polo infinitivo precedido da preposición a: leva desde onte maquinando / a maquinar nesa cuestión; anda rosmando / a rosmar polas esquinas; está chovendo / a chover a chuzos; seguía pensando / a pensar o mesmo, etc. En todos estes exemplos o significado imperfectivo das perífrases é o mesmo (refírense sempre á fase media ou central da acción) independentemente de que se expresen con xerundio ou coa estrutura ' $a$ + infinitivo', porque esta ten tamén un valor xerundial.

Nalgunhas gramáticas tipifícase a construción con ' $a+$ infinitivo' como 'dialectal e innovadora' e chámase a atención sobre os abusos hiperenxebristas que se fan da mesma ás veces na lingua culta, ao utilizala mesmo 
en contextos que non a admiten (ver, por ex. Álvarez e Xove, 2002: 361). Non obstante, non hai dúbida do seu carácter tradicional no idioma en parte do territorio lingüístico galego, aínda que, como sucede tamén con outras estruturas, nos atopemos nunha conxuntura na que se poden producir coincidencias aparentemente sorprendentes nas escollas lingüísticas entre polos idiomáticos moi afastados: neste caso entre falantes populares que a recibiron por vía tradicional e outro tipo de usuarios que posiblemente botan man dela por razóns diferencialistas e a miúdo con moi pouco rigor.

Está, por iso, moi fundada a preocupación de destacados estudosos do idioma pola expansión acrítica de certas formas tradicionais pero minoritarias do galego, como pode ser a que estamos comentando. Como moi ben indica R. Álvarez (1994: 24), "falta un pronunciamento da gramática normativa sobre a extensión á xeneralidade do galego da forma dialectal coñecida como infinitivo xerundial (...) e cómpre unha descrición o máis exacta posible do seu ámbito de uso, para impedir que esa ampliación territorial vaia acompañada dunha extensión das posibilidades reais de funcionamento". Porén, estas cautelas tampouco nos deben levar a estimular a exclusividade da forma máis estendida coa consecuencia indirecta da desaparición da minoritaria.

O mesmo ca na estrutura analizada no apartado 4.1, o que pretendemos valorar na nosa investigación en relación con estoutra construción é o seguinte:

-Comprobar se se sente estraña a perífrase ' $a+$ infinitivo' ata o punto de considerala incorrecta (probas 1 e 4).

- Observar se na escolla entre o xerundio e o infinitivo xerundial para completar o texto (proba 2) ou para realizar a tradución do castelán (proba 3) se opta preferentemente pola primeira posibilidade ou pola segunda.

-Coñecer o grao de identificación da poboación da mostra en relación con cada unha das alternativas e a súa distribución en función de variables sociolingüísticas, de hábitat e dialectais (proba 4).

Dado que en castelán este significado durativo só se pode conseguir a través dunha perífrase con xerundio (está jugando al fútbol; pero non *está a jugar al fútbol), unha identificación excluínte do alumnado coa forma galega coincidente coa castelá (a do xerundio) podería hipoteticamente poñerse en relación co que denominamos 'interferencia de converxencia', consistente en que os falantes se van decantando cara á forma común nas dúas linguas en prexuízo da forma máis discrepante, ata o punto de que esta última acaba 
desaparecendo das escollas espontáneas e mesmo sendo sentida como estraña. En cambio, unha preferencia maioritaria polo infinitivo xerundial, dado o seu carácter de variedade minoritaria no conxunto do territorio do galego, seguramente indicaría que o alumnado da mostra se sente condicionado por un afán diferencialista en relación co castelán; é dicir, por unha 'interferencia de diverxencia'.

Para a análise valémonos dos seguintes textos nas probas 1, 2 e 3:

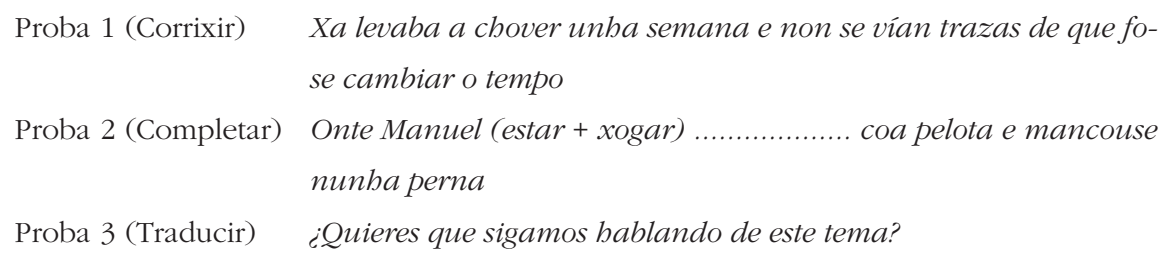

Na proba 4 completábase a indagación sobre a relación dos estudantes con esta dobre forma da perífrase formulándolles dúas preguntas (unha sobre corrección / incorrección e outra sobre identificación) a partir de tres textos: o primeiro coa forma verbo $+x e r u n d i o$, o segundo con verbo $+a+$ infinitivo e o terceiro nunha construción con xerundio pero anormativa pola posición incorrecta do clítico. Os textos eran os seguintes:

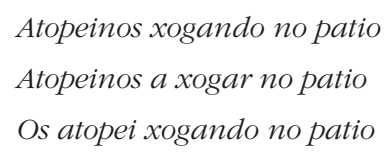

A continuación presentamos os resultados obtidos, en primeiro lugar nas probas 1,2 e 3, e, despois, na proba 4:

\begin{tabular}{|c|c|c|c|}
\hline & Construción co xerundio & Construción co infinitivo xerundial & Outras / N.C. \\
\hline Proba 1 & $756(65 \%)$ & $389(33,5 \%)$ & $17(1,5 \%)$ \\
\hline Proba 2 & $711(61,2 \%)$ & $394(33,9 \%)$ & $57(4,9 \%)$ \\
\hline Proba 3 & 1108 (95,4\%) & $42(3,6 \%)$ & $12(1 \%)$ \\
\hline
\end{tabular}

Entendemos que os datos máis categóricos son os da proba $\mathrm{n}^{\circ} 1$, que nos mostran que practicamente dous de cada tres estudantes (o 65\%) consideraron incorrecto o sintagma a chover, substituíndoo, en consecuencia, pola forma do xerundio chovendo.

Os resultados da proba 2 son concordantes cos da 1 (o 33,9\% fan uso do infinitivo xerundial), pero discrepan de maneira moi importante $\cos$ da 3 , onde o sintagma ' $a+$ infinitivo' só é utilizado polo 3,6\% da mostra. Conside- 
ramos que esta discrepancia en dúas probas que, sendo diferentes, coinciden en estaren orientadas ao uso lingüístico se explica parcialmente pola literalidade dos textos: a presenza explícita do infinitivo no estímulo lingüístico que se ofrece na proba 2 (estar $+\underline{x o g a r})$ puido inducir a un número determinado de estudantes a optar polo infinitivo xerundial; mentres que a construción con xerundio do texto castelán da proba 3 (sigamos hablando) puido favorecer o recurso a esa mesma forma verbal en galego.

Polo que se refire á proba no 4, os datos sobre 'corrección / incorrección' e sobre 'identificación' foron os seguintes:

\begin{tabular}{lcc}
\multicolumn{3}{c}{ Opinión sobre corrección ou incorrección (Proba 4) } \\
& Correcto & Incorrecto \\
1. Atopeinos xogando no patio & $96,9 \%$ & $3,1 \%$ \\
2. Atopeinos a xogar no patio & $48,2 \%$ & $51,8 \%$ \\
3. Os atopei xogando no patio & $28,9 \%$ & $71,1 \%$
\end{tabular}

Como era de esperar, non ofrece dúbidas a corrección da construción $\mathrm{n}^{\circ} 1$ (só un residual 3,1\% a considera incorrecta) e achégase ao 30\% a porcentaxe de estudantes que considera correcta a $\mathrm{n}^{\circ} 3$; un dato preocupante desde o punto de vista normativo, pero que non se relaciona coa formación da perífrase, que é o que aquí nos ocupa.

No tocante á construción $n^{\circ} 2$, que é a que realmente nos interesa neste apartado, vemos que hai máis estudantes que a consideran incorrecta ca correcta $(51,8 \%$ e 48,2\%); unhas porcentaxes que sen chegaren ás da proba 1 , confirman que o infinitivo xerundial como alternativa para construír perífrases durativas coma as do texto é rexeitado por anormativo pola maioría do alumnado da mostra.

No tocante á pregunta sobre 'identificación', os datos globais que se recollen na seguinte táboa indican que a estrutura normativa con xerundio é a que lle resulta máis familiar á inmensa maioría do alumnado (86,9\%), mentres que as outras dúas (a construción galega co infinitivo xerundial e o calco sintáctico do castelán) obteñen porcentaxes de identificación case idénticas e moi minoritarias.

Porcentaxes globais de identificación con cada estrutura (Proba 4)

$\begin{array}{lc}\text { 1. Atopeinos xogando no patio } & 86,9 \% \\ \text { 2. Atopeinos a xogar no patio } & 6,5 \% \\ \text { 3. Os atopei xogando no patio } & 6,6 \%\end{array}$


$\mathrm{Na}$ distribución dos resultados de identificación co infinitivo xerundial en función das distintas variables da mostra (sociolingüísticas, de hábitat e escolares) non se observan diferenzas significativas. Pola contra, apréciase unha certa correlación co mapa dialectal deste fenómeno lingüístico (ver, por exemplo, Fernández Rei, 1990): a porcentaxe de identificación con esta construción sitúase entre o $10 \%$ e o $20 \%$ en centros situados en territorio no que o infinitivo xerundial é tradicional (por exemplo, Moraña ou O Porriño), mentres que non chega ao 5\% noutros nos que esta construción non ten raíces históricas (coma Vila de Cruces ou Viveiro).

Como síntese, e referíndonos especialmente á construción co infinitivo xerundial, por ser a forma marcada pola súa diverxencia co castelán, podemos destacar o seguinte:

a) En relación coa dimensión corrección / incorrección, que é a que nos dá unha información máis categórica, observamos que o número de estudantes que considera que a perífrase co infinitivo xerundial é incorrecta supera aos que entenden que é correcta: na proba 1 son practicamente dous de cada tres (o 65\%) os que substitúen o texto Xa levaba a chover por Xa levaba chovendo, e, na proba 4, a porcentaxe dos que consideraron incorrecto o texto Atopeinos a xogar no patio supera tamén, aínda que cunha marxe máis estreita, aos que o aceptaron como correcto (o 51,8\% fronte ó 48,2\%).

b) Sobre a porcentaxe de alumnado que escolle o infinitivo xerundial para construír os textos das probas 2 e 3, os datos son menos definidos e posiblemente están condicionados polos estímulos lingüísticos presentes nos mesmos: na proba 2, un de cada tres estudantes transforma estar + xogar en estar a xogar (a mesma porcentaxe, o 33,9\%, que consideraba 'correcta' na proba 1 a perífrase con ' $a+$ infinitivo); pero na proba 3 só un 3,6\% opta por converter a perífrase castelá sigamos hablando en sigamos a falar. Unha diferenza tan marcada na escolla do xerundio ou do infinitivo xerundial para construír a perífrase, sen ningunha variación no contexto de realización das probas, parece que hai que relacionala coa tarefa que se demandaba en cada unha e coa mesma textualidade dos enunciados que se ofrecían: presenza explícita do infinitivo na $2^{\mathrm{a}}$ (xogar) e do xerundio na $3^{\mathrm{a}}$ (hablando).

c) A pregunta sobre 'identificación' da proba 4 demostra que só unha minoría moi reducida (o 6,5\%) afirma que se sente máis identificada coa perífrase Atopeinos a xogar no patio; exactamente a mesma porcentaxe cós que mostran unha maior familiaridade co texto anormativo Os atopei xogando no patio. Como era de esperar, a inmensa maioría 
(o 86,9\%) indica que se sente máis identificada coa perífrase con xerundio Atopeinos xogando.

A distribución da porcentaxe global de identificación obtida pola perífrase co infinitivo xerundial atendendo ás variables da mostra confirma que a maior parte delas son pouco significativas: a distribución por titularidade do centro, por hábitat e polas distintas variables sociolingüísticas ou escolares non perfila grupos claramente diferenciados, non podendo, en consecuencia, afirmarse que a maior familiaridade con esta construción se corresponda con ningún colectivo concreto.

A distribución territorial destes datos sobre identificación co infinitivo conxugado ofrece resultados superiores nos centros situados en localidades nas que esa estrutura é tradicional, pero trátase en todos os casos de porcentaxes moi minoritarias que non permiten afirmar que haxa unha distribución territorial claramente marcada, nin moito menos que existan zonas nas que esta construción sexa preponderante.

\section{3. Infinitivo flexionado e infinitivo non flexionado}

$\mathrm{Na}$ exemplificación que estamos a realizar sobre o coñecemento e a vitalidade dalgunhas estruturas morfosintácticas que teñen unha realización converxente co castelán e outra diverxente, referirémonos finalmente ás formas flexionadas e non flexionadas do infinitivo.

Como describen todas as gramáticas, o galego dispón para o infinitivo dunha forma invariable e doutra variable en concordancia co seu suxeito, constituíndo esta última un dos trazos máis singulares da súa morfoloxía verbal en relación co castelán, que só coñece a forma invariable. Pero estas dúas formas do infinitivo non funcionan en galego en distribución libre; en concreto, o infinitivo flexionado, por ser a forma marcada, ten limitado o seu uso a certos contextos e non é obrigado en ningún caso.

Entre as condicións que favorecen a súa aparición os estudos gramaticais citan, por orde de importancia, os seguintes: que o infinitivo teña un suxeito diferente do do verbo principal (O accidente produciuse ó irmos para a casa); se o suxeito é o mesmo, que a oración de infinitivo vaia anteposta (en vez de quedardes parados, poñédevos a traballar); e, no caso de ser o mesmo suxeito e ir posposta a oración de infinitivo, que este vaia distanciado do verbo principal (Ilusionáronse moito coa idea de seren eles mesmos os organizadores do acto).

En contextos distintos dos expresados no parágrafo anterior o infinitivo flexionado é menos habitual e, nalgúns casos, mesmo está excluído. Isto último sucede, por exemplo, en situacións como as seguintes: cando non é realmente verbo ou cando carece de suxeito (Querer é poder; Tanto traballar 
para nada...); cando o infinitivo é o verbo auxiliado dunha perífrase verbal ou cando forma parte dun complexo verbal (Tiveron que escoitar o que non querian; Puxéronse a conversar coma se se coñecesen de sempre...), entre outras.

A cuestión do uso social da forma flexionada do infinitivo parece estar sufrindo cambios substanciais que, posiblemente, gardan paralelismo co que xa comentamos en relación coa escolla da estrutura ' $a+$ infinitivo' como forma da perífrase durativa en vez do xerundio: de seren preferentemente construcións tradicionais inseridas no galego popular, están pasando a ser, cada vez máis, recursos da lingua culta (tanto oral coma escrita), chegando nalgúns casos ó abuso hiperenxebrista. Este proceso, explicable pola conxuntura histórica na que se atopa a lingua galega, parece que discorre parello, porén, a outro de tendencia inversa: a desaparición progresiva desta forma na fala espontánea e a ocupación dos seus usos máis específicos polo infinitivo non flexionado.

Os textos utilizados nas probas 1, 2 e 3 para explorar o comportamento lingüístico dos estudantes en relación con este fenómeno lingüístico foron os seguintes:

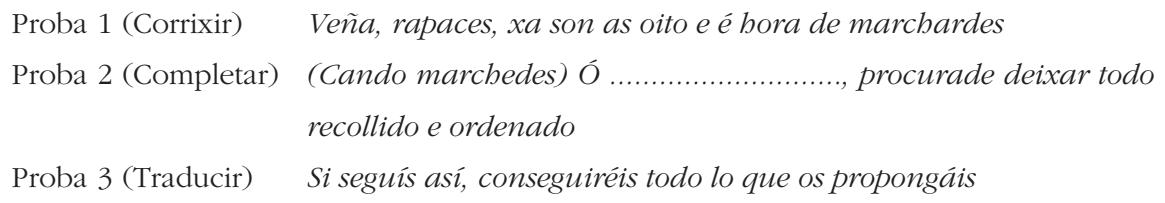

Os exemplos seleccionados responden a contextos nos que estaría indicada a forma flexionada (...é hora de marchardes; Ó marchardes...; De seguirdes asi...); pero, como xa se sinalou, en todos eles é posible tamén o infinitivo non flexionado ou unha construción modotemporal (...é hora de que marchedes; Cando marchedes...; Se seguides así...). Por iso, a información máis categórica será a que nos acheguen as respostas á proba 1, que nos permitirá saber cántos estudantes se senten distanciados da forma flexionada ata o punto de considerala incorrecta, e, en segundo lugar, a opción que se escolla na proba 2 entre a forma flexionada e a non flexionada. As respostas ao texto da proba $n^{\circ} 3$, en cambio, deben ser valoradas con outro criterio: ao estar construído en forma modotemporal, o esperable é unha tradución ao galego neste mesmo formato, de maneira que o único que se pode valorar son as desviacións que se produzan sobre esta resposta esperada e facer unha interpretación máis cualitativa das mesmas.

Esta construción trátase tamén na proba 4, onde, como vimos noutros fenómenos xa comentados, se indaga, en primeiro lugar, sobre a percepción que 
teñen os estudantes da corrección ou incorrección da forma flexionada ao lado da non flexionada e doutra forma inexistente no sistema da lingua galega, e, en segundo termo, sobre a estrutura coa que se senten máis identificados. Os textos propostos para explorar estas dúas cuestións foron os seguintes:

Ó virdes para a casa, recollédeme no Instituto

Ó vir para a casa, recollédeme no Instituto

ó viñerdes para a casa, recollédeme no Instituto.

Os resultados obtidos nas probas 1, 2 e 3 foron os seguintes:

Frecuencias e porcentaxes conseguidas por cada opción (Probas 1, 2 e 3)

\begin{tabular}{lccc}
\hline & $\begin{array}{c}\text { Construción co infinitivo } \\
\text { flexionado }\end{array}$ & $\begin{array}{c}\text { Construción co infinitivo } \\
\text { non flexionado }\end{array}$ & Outras posibilidades \\
\hline Proba 1 & $686(59 \%)$ & $305(26,3 \%)$ & $171(14,7 \%)$ \\
Proba 2 & $9(0,8 \%)$ & $972(83,6 \%)$ & $181(15,6 \%)$ \\
Proba 3 & $2(0,2 \%)$ & $14(1,2 \%)$ & $1146(98,6 \%)^{*}$ \\
\hline
\end{tabular}

*Construción modotemporal

A disparidade dos resultados das tres probas hai que relacionala coas moi diferentes tarefas que se demandaban en cada unha:

-A máis categórica, sen dúbida, era a da proba 1, na que o que tiñan que facer os estudantes era subliñar e corrixir desviacións normativas no caso de habelas. Os datos da táboa indican que só o 59\% considerou correcto o texto e que o restante $41 \%$ atopou algún problema normativo na construción flexionada do infinitivo, resolvéndoo da seguinte maneira: o 26,3\% cambiando a forma flexionada (marchardes) pola non flexionada (marchar) e o 14,7\% buscando outras fórmulas.

-Os resultados das probas 2 e 3 mostran unhas porcentaxes absolutamente insignificantes no emprego do infinitivo flexionado: na $\mathrm{n}^{\circ} 2$ só o $0,8 \%$ completou o texto na forma $O$ marchardes, e na $\mathrm{n}^{\circ} 3$ foi a penas o $0,2 \%$ o que traduciu a frase castelá como De seguirdes así... De calquera maneira, como xa se indicou máis arriba, o valor destes datos cómpre relativizalos, especialmente os da proba $\mathrm{n}^{\circ} 3$, debido a que a construción modotemporal do texto castelán remite espontaneamente a unha construción similar en galego.

Polo que se refire á proba 4, tanto no que se refire á opinión sobre 'corrección / incorrección' de cada texto coma á escolla daquel co que máis se identificaban, os resultados foron os seguintes: 


\begin{tabular}{lcc}
\multicolumn{3}{c}{ Opinión sobre corrección ou incorrección (Proba 4) } \\
Correcto & Incorrecto \\
1. Ó virdes para a casa, recollédeme no Instituto & $67,6 \%$ & $32,4 \%$ \\
2. Ó vir para a casa, recollédeme no Instituto & $89,8 \%$ & $10,2 \%$ \\
3. Ó viñerdes para a casa, recollédeme no Instituto & $6,1 \%$ & $93,9 \%$ \\
& \\
Porcentaxes globais de identificación con cada estrutura (Proba 4) \\
1. Ó virdes para a casa, recollédeme no Instituto \\
2. Ó vir para a casa, recollédeme no Instituto \\
3. Ó viñerdes para a casa, recollédeme no Instituto & $83,1 \%$
\end{tabular}

Como se pode apreciar, case un terzo da mostra (o 32,4\%) considerou incorrecta a construción co infinitivo flexionado, unha porcentaxe que se corresponde bastante coa que na proba 1 corrixía como incorrecta esta construción: o 26,3\% substituía alí esta forma pola non flexionada e aínda había un $14,7 \%$ máis que ofrecía outras alternativas. As opinións sobre as outras dúas construcións seguramente son máis esperables.

No tocante á 'identificación' os datos globais mostran tamén unha esperada preferencia pola forma non flexionada por parte do $83,1 \%$ dos estudantes da mostra fronte a un 15,5\% que manifestan sentir unha maior familiaridade coa forma flexionada. O aspecto máis sorprendente xorde no momento de distribuír estas porcentaxes atendendo ás variables da mostra, porque se observa que son os colectivos máis urbanos e de perfil menos galegófono os que manifestan unha maior identificación co infinitivo flexionado (as diferenzas entre os que residen en ámbitos rurais e urbanos achégase aos 20 puntos, e entre os que falan habitualmente galego e os castelanfalantes habituais supera os 10; en ambos os dous casos, a favor dos segundos). Esta distribución contrasta co que sucedía coa construción diverxente na perífrase 'ter / haber que + infinitivo' ou co 'infinitivo xerundial', nos que, con maior ou menor énfase, eran sempre os individuos do rural e máis galegófonos os que acadaban porcentaxes máis elevadas.

Como síntese, e centrándonos unha vez máis na estrutura diverxente co castelán, o máis subliñable en relación coa alternativa 'infinitivo flexionado / infinitivo non flexionado' entendemos que é o seguinte:

a) No tocante á cuestión máis categórica das probas, a da aceptación do infinitivo flexionado como acorde coa norma da lingua galega, sorprende a alta porcentaxe dos que o consideran anormativo: o $41 \%$ dos estudantes corrixiu no texto da proba 1 a forma flexionada marchardes (o 26,3\% substituíndoa pola correspondente non flexionada mar- 
char e o $14,7 \%$ restante por outras correspondencias non sempre normativas), e o $32,4 \%$ considerou tamén incorrecto na proba 4 o texto co infinitivo conxugado (ó virdes para a casa...).

b) No referente á escolla da forma flexionada para construír os textos das probas 2 e 3, só o fixo unha porcentaxe insignificante de estudantes (o $0,8 \%$ na segunda e o $0,2 \%$ na terceira), aínda que, como xa se comentou na descrición destes resultados, existen factores condicionantes da escolla (especialmente na proba 3) que nos obrigan a tomar estes datos con reservas.

c) A pregunta sobre 'identificación' da proba 4 demostra que os estudantes se senten moito máis próximos á construción non flexionada (o 83,1\%) ca á flexionada (o 15,5\%). O resultado, sen dúbida esperable, non parece mostrar 'contaminación' polo contexto académico no que se realiza a proba; un contexto que podería inducir a respostas máis favorables á alternativa flexionada, por ser habitualmente un obxecto de atención destacado nos programas escolares de lingua galega.

A estratificación dos resultados sobre identificación por variables sociolingüísticas e de hábitat presenta uns datos que poden resultar sorprendentes: os colectivos que tradicionalmente se veñen asociando co galego popular (os que residen no rural, os que teñen o galego como lingua inicial, os que falan habitualmente en galego) son os que mostran menor identificación coa forma flexionada do infinitivo. Esta distribución parece indicar que o infinitivo flexionado se asocia máis con novos ámbitos de uso do galego ca co galego tradicional; todo o contrario do que comprobamos en relación coas outras estruturas 'marcadas' que comentamos en epígrafes anteriores.

\section{REFERENCIAS BIBLIOGRÁFICAS}

Álvarez, R. (1994): "Gramática descritiva e gramática prescritiva", en Cadernos de lingua 10, Real Academia Galega.

Álvarez, R. (et al.) (1986): Gramática Galega, Vigo, Galaxia.

Álvarez, R. e Xove, X. (2002): Gramática da lingua galega, Vigo, Galaxia.

Blas Arroyo, J.L. (1993): La interferencia lingüistica en Valencia (dirección catalán-español), Castellón, Univ. Jaume I.

Coseriu, E. (1977): "Sprachliche Interferenz bei Hochgebildeten", en Kolb, H. e Lauffer, H. (eds.) Sprachliche Interferenz, Festschrift für Werner Betz, Tübingen, Niemeyer, pp. 77-100.

Fernández Rei, F. (1990): Dialectoloxía da lingua galega, Vigo, Edicións Xerais. 
Gómez Torrego, L. (1994): Manual de español correcto II, Madrid, Arco/Libros.

Hernández, C. (1997): "Algunas propuestas didácticas para trabajar la interferencia catalán-español en el ámbito universitario”, en Didáctica de la Lengua y la Literatura para una Sociedad Plurilingüe del siglo XXI, Universitat de Barcelona, pp 633-639.

Hernández, C. (1998): Algunas cuestiones más sobre el contacto de lenguas: estudio de la interferencia lingüistica del catalán en el español de Cataluña, Univ. de Barcelona, (Tese de doutoramento / Microforma).

Kabatek, J. (1991): "Interferencias entre o galego e castelán: Problemas do galego estándar", en Cadernos de Lingua 4, pp. 39-48.

Kabatek, J. (2000): Os falantes como lingüistas, Vigo, Edicións Xerais.

Lope Blanch, J.M. (1981): "Influencia del contacto lingüístico en el español de América", en Cvitanovic e Fontanella de Weimberg (eds.): Simposio Internacional de Lengua y Literaturas Hispánicas, Bahía Blanca.

Malmberg, B. (1959): "L'extension du castillan et le problème des substrats, en Actes du Colloque International de Civilisations, Litteratures et Langues Romanes, Bucarest, pp. 249-260.

Payrató, Ll. (1985): La interferència lingüística, Barcelona, Curial Edicions Catalanes - Publicacions de l'Abadía de Montserrat.

Sala, M. (1998): Lenguas en contacto, Madrid, Gredos ( $1^{\mathrm{a}}$ ed. 1986, Centro de Lingüística Hispánica de la UNAM, México).

Thomason, S. G. (2000): "On the unpredictability of contact effects", en Estudios de sociolingüistica 1.1, pp. 173-182, Universidade de Vigo.

Thomason, S. G. e Kaufman, T. (1988): Language Contact, Creolization and Genetic Linguistics, Berkeley, University of California Press.

Van Overbeke, M. (1976): Les mécanismes de l'interférénce linguistique, Ed. Fragua, Madrid.

Weinreich, U. (1953): Languages in contact. Findings and problems, The Hague, Mouton. (Cítase por trad. Castelá: Lenguas en contacto. Descubrimientos y problemas, Caracas, Ed. Biblioteca de la Univ. Central, 1974). 